\title{
Posterior cruciate ligament, exploring the unknown
}

\author{
Asbjørn Årøen · Peter Verdonk
}

Received: 11 October 2012/ Accepted: 28 January 2013/Published online: 13 February 2013

(C) Springer-Verlag Berlin Heidelberg 2013

The posterior cruciate ligament (PCL) is the strongest ligament of the knee, but it is rarely reconstructed in isolation. Although generally accepted that multi-ligamentous knee injuries involving PCL requires operative intervention, the treatment of PCL injuries in isolation is less clearcut and a point of controversy. The need for operative treatment of isolated PCL injuries has been reported to be as low as $3 \%$ [6]. Several reasons can be put forward as to why this is in common practice; however, it is well known that some patients with this injury have significantly reduced knee function and improved knee stability after surgery [1]. On the other side, there are plenty of examples on top athletes, who have sustained PCL injuries, who have been able to return to their sports without surgical intervention [7]. The line between surgical and non-surgical approach is blurred and represents a definite challenge for the knee surgeon to provide the best advice to the individual patient.

The lack of consensus on the treatment of PCL injuries would suggest that international collaboration is needed in order to make progress in this field of knee surgery. The ESSKA organization U45 committee has committed to focus on this area over the last 2 years. The U45 members agreed that anatomy, symptoms, evaluation, surgery and rehabilitation were the most pertinent issues to explore. During the ESSKA Congress in May 2012, a symposium

\footnotetext{
A. Årøen $(\bowtie)$

Oslo Sports Trauma Research Center and Department of Orthopedic Surgery, Akershus University Hospital, University of Oslo, 1478 Lørenskog, Norway

e-mail: asben@online.no; asbjorn.aroen@medisin.uio.no

P. Verdonk

Department of Physiotherapy and Orthopaedic Surgery,

Ghent University, Ghent, Belgium
}

and ICL were dedicated to discuss and highlight these matters. The U45 committee decided early in their work to publish a special issue in KSST journal to focus on subjects related to the PCL. The results from this work are found in this issue of the journal, and the committee has been fortunate to have gained from the extensive experience of Professor Robert LaPrade and his group, who have produced two very detailed review papers outlining the current evidence-based guidelines for the use of PCL braces and rehabilitation in this difficult knee injury $[4,5]$. The current issue also contains two very informative papers on the surgical anatomy: the first, by Van Hoof et al. [8], describes a novel technique using 3D CT to delineate the PCL, while the second, by Hatsushika et al. [3] provides an accurate description of the individual fibres, which comprise each bundle of the PCL. As always in surgery, understanding the anatomy is the key to success, and given the published results on PCL surgery, a review of the surgical anatomy represents one of the most important key stones in continuing to make progress in this area. As surgeons, we always have to be aware of the variation in anatomy and function. Over the past 10 years, great strides have been made in furthering our understanding in the anatomy and biomechanics of the anterior cruciate ligament (ACL) and posterolateral corner, in addition to the development of better and more effective reconstruction techniques. We can be heartened that further advancements can also be made in PCL surgery.

Registry data from the Norwegian Knee Ligament Registry, published in this issue of the journal, demonstrate that patients with isolated PCL injuries are significantly more disabled than those with ACL injuries; however, it takes a median of 21 months from the index injury before the decision to intervene operatively and perform a reconstruction is made [2]. 
It has been well established that the two bundles of PCL have different functions throughout the range of motion of the knee. Consequently, single-bundle ruptures are known to occur, and therefore, it seems appealing to reconstruct only the ruptured bundle by augmenting the injured PCL with a single-bundle reconstruction. Additionally, more of the native PCL tissue will be preserved with an augmentation procedure with a single-bundle reconstruction. A systematic review, presented in this issue, informs the reader about the evidence for this point of view.

Although there are a number of good studies, which exist on isolated PCL injuries, we need more knowledge to progress and we believe that a further initiative is warranted in order to continue our advancement. Maybe, it is time for the ESSKA to establish a PCL committee in order to establish a forum where ESSKA members are encouraged to increase their efforts in producing studies and establishing instructional courses to gain further knowledge on the treatment of this injury. Hopefully, this editorial will be a call for action to facilitate further collaboration among the members as illustrated by the PCL studies in the current issue of the journal.

\section{References}

1. Ahn JH, Lee YS, Choi SH, Chang MJ, Lee DK (2011) Singlebundle transtibial posterior cruciate ligament reconstruction using a bioabsorbable cross-pin tibial back side fixation. Knee Surg Sports Traumatol Arthrosc. doi:10.1007/s00167-011-1769-5

2. Aroen A, Sivertsen EA, Owesen C, Engebretsen L, Granan LP (2012) An isolated rupture of the posterior cruciate ligament results in reduced preoperative knee function in comparison with an anterior cruciate ligament injury. Knee Surg Sports Traumatol Arthrosc. doi:10.1007/s00167-012-2132-1

3. Hatsushika D, Nimura A, Mochizuki T, Yamaguchi K, Muneta T, Akita K (2012) Attachments of separate small bundles of human posterior cruciate ligament: an anatomic study. Knee Surg Sports Traumatol Arthrosc. doi:10.1007/s00167-012-2224-y

4. Jansson KS, Costello KE, O'Brien L, Wijdicks CA, Laprade RF (2012) A historical perspective of PCL bracing. Knee Surg Sports Traumatol Arthrosc. doi:10.1007/s00167-012-2048-9

5. Pierce CM, O'Brien L, Griffin LW, Laprade RF (2012) Posterior cruciate ligament tears: functional and postoperative rehabilitation. Knee Surg Sports Traumatol Arthrosc. doi:10.1007/s00167012-1970-1

6. Shelbourne KD, Davis TJ, Patel DV (1999) The natural history of acute, isolated, nonoperatively treated posterior cruciate ligament injuries. A prospective study. Am J Sports Med 27(3):276-283

7. Toritsuka Y, Horibe S, Hiro-Oka A, Mitsuoka T, Nakamura N (2004) Conservative treatment for rugby football players with an acute isolated posterior cruciate ligament injury. Knee Surg Sports Traumatol Arthrosc 12(2):110-114

8. Van Hoof T, Cromheecke M, Tampere T, D'Herde K, Victor J, Verdonk PC (2012) The posterior cruciate ligament: a study on its bony and soft tissue anatomy using novel 3D CT technology. Knee Surg Sports Traumatol Arthrosc. doi:10.1007/s00167-012-2332-8 